\title{
Inducible Heme Oxygenase in the Kidney: a Model for the Homeostatic Control of Hemoglobin Catabolism
}

\author{
Neville R. Pimstone, Peter Engel, Raimo Tenhunen, Paul T. Seitz, \\ Harvey S. Marver, and Rudi Schmid \\ From the Department of Medicine, University of California, San Francisco \\ Medical Center, San Francisco, California 94122, and the Department of \\ Clinical Chemistry, Meilahti Hospital, University of Helsinki, \\ Helsinki 29, Finland
}

\begin{abstract}
A в S T R A C T We have recently identified and characterized NADPH-dependent microsomal heme oxygenase as the major enzymatic mechanism for the conversion of hemoglobin-heme to bilirubin-IX $\alpha$ in vivo. Enzyme activity is highest in tissues normally involved in red cell breakdown, that is, spleen, liver, and bone marrow, but it usually is negligible in the kidney. However, renal heme oxygenase activity may be transiently increased 30 - to 100 -fold following hemoglobinemia that exceeded the plasma haptoglobin-binding capacity and consequently resulted in hemoglobinuria. Maximal stimulation of enzyme activity in rats is reached 6-16 hr following a single intravenous injection of $30 \mathrm{mg}$ of hemoglobin per $100 \mathrm{~g}$ body weight; activity returns to basal levels after about $48 \mathrm{hr}$. At peak level, total enzyme activity in the kidneys exceeds that of the spleen or liver. Cyclohexamide, puromycin, or actinomycin $\mathrm{D}$, given just before, or within a few hours after, a single intravenous injection of hemoglobin minimizes or prevents the rise in renal enzyme activity; this suggests that the increase in enzyme activity is dependent on continued synthesis of ribonucleic acid and protein. The apparent biological half-life of renal heme oxygenase is about
\end{abstract}

This work was presented in part at the Annual Meeting of the American Society for Clinical Investigation, Atlantic City, N. J., May 1970 (1). Dr. Pimstone's present address is the Department of Medicine, University of Cape Town, P. O. Box 594, Cape Town, Republic of South Africa.

Dr. Marver died 11 July 1971.

Peter Engel was a Predoctoral Research Fellow from Duke University.

Dr. Pimstone is the recipient of an International Postdoctoral Research Fellowship F05-TW-1360; Dr. Marver was the recipient of Research Career Development Award K04AM-14301 from the National Institutes of Health; and Dr. Tenhunen's work was supported by the National Research Council for Medical Sciences, Finland.

Received for publication 19 February 1971.
$6 \mathrm{hr}$. These observations indicate that functional adaptation of renal heme oxygenase activity reflects enzyme induction either directly or indirectly by the substrate, hemoglobin.

Filtered rather than plasma hemoglobin appears to regulate renal heme oxygenase activity. Thus, stabilization of plasma hemoglobin in its tetrameric form with bis ( $N$-maleimidomethyl) ether, which diminishes its glomerular filtration and retards it plasma clearance, results in reduced enzyme stimulation in the kidney, but enhances its activity in the liver. These findings suggest that the enzyme is localized in the tubular epithelial cells rather than in the glomeruli and is activated by luminal hemoglobin. Direct support for this concept was obtained by the demonstration of heme oxygenase activity in renal tubules isolated from rabbits that had been injected with hemoglobin.

\section{INTRODUCTION}

Recent studies have defined an enzymatic mechanism by which the heme moiety of hemoglobin is converted to bile pigment $(2-4)$. The rate-limiting enzyme is heme oxygenase, which is a microsomal enzyme containing cytochrome $\mathrm{P} 450$ as the terminal oxidase $(4,5)$. It catalyzes the oxidation of heme at the $\alpha$-methene bridge (3) to form equimolar amounts of biliverdin and of carbon monoxide (5). The biliverdin then is reduced to bilirubin by the NADPH-dependent soluble enzyme, biliverdin reductase $(6,7)$.

Heme oxygenase is most active in organs normally engaged in the sequestration and breakdown of senescent red cells, namely spleen, liver, and bone marrow (5). Its activity in rat spleen, as determined in vitro, is in good agreement with the requirements for the normal turnover of erythrocyte-hemoglobin in the intact 
animals (2). After splenectomy, or in conditions where the turnover of hemoglobin is accelerated, for instance in hemolytic anemia $(4,5)$, hepatic heme oxygenase activity is elevated reflecting the increased amount of hemoglobin that is removed by the liver (8). Similarly, enzyme activity is enhanced in isolated peritoneal or alveolar macrophages that, in vivo, have ingested hemin or hemoglobin before being harvested (9). These findings leave little doubt that the activity of heme oxygenase is controlled by the amount of heme that is offered for catabolism. The nature of this regulatory mechanism is described in the present report, using the response of the kidney to hemoglobinuria as the experimental model.

As the kidney normally is not involved in the breakdown of red cells or hemoglobin, it expectedly has very low levels of heme oxygenase activity (5). However, in severe intravascular hemolysis, when hemoglobin released from circulating red cells exceeds the binding capacity of the plasma haptoglobin (10), unbound hemoglobin may be filtered by the renal glomeruli and appear in the urine (11). From the study of Bunn and Jandl (12), it would appear that in hemoglobinemia with hemoglobinuria, the kidney may be able to catabolize part of the filtered hemoglobin that has been reabsorbed by proximal convoluted tubules (13-16). If this were the case, one would expect the kidney to respond to hemoglobinuria with increased heme oxygenase activity and one would further predict that this adaptive mechanism is localized in the tubular epithelial cells. We have investigated this relationship under optimal experimental conditions in rats made hemoglobinuric with intravenous injections of hemoglobin.

\section{METHODS}

Most experiments were carried out in female SpragueDawley rats, weighing 250-350 g. The animals had free access to water and to Berkeley Diet Chow (Berkeley Biologicals, Berkeley, Calif.). In studies requiring analysis of urine, rats were housed in metabolic cages permitting uninterrupted and quantitative urine collection.

Rat hemoglobin was obtained as outlined by Bunn, Esham, and Bull (11). Isotopically labeled rat hemoglobin was prepared by the method of Keene and Jandl (17) using ${ }^{59} \mathrm{FeCl}_{3}$ (Tracer Lab, Waltham, Mass.) as isotopic precursor. The hemoglobin was complexed with bis $(N$-maleimidomethyl) ether $(B M E)^{1}$ as described by Bunn et al. (11). Titration of the reactive sulfhydryl groups of hemoglobin solutions treated with $\mathrm{BME}^{2}$ (18) indicated that the reaction had gone to completion. The concentration of hemoglobin in these solutions, measured as cyanmethemoglobin (19), was usually between 40 and $60 \mathrm{mg}$ per $\mathrm{ml}$. In rat urine, the hemoglobin concentration was measured by the benzidine method (20). Radioactivity in samples containing ${ }^{60} \mathrm{Fe}$ was measured in a well-type scintillation counter (Nuclear-

\footnotetext{
${ }^{1}$ Kindly supplied by Uniroyal Inc., Wayne, N. J.

${ }^{2}$ Abbreviations used in this paper: $\mathrm{BME}$, bis $(N$-maleimidomethyl) ether.
}

Chicago Corp., Des Plaines, I11.) for a minimum of either $10 \mathrm{~min}$ or 10,000 counts. For these determinations, one whole kidney, or $1 \mathrm{ml}$ of blood or urine, or suitable portions thereof, diluted to $1 \mathrm{ml}$ with distilled water, were used. Microsomal heme oxygenase activity was determined on $20,000 g$ supernatant fractions of tissue homogenates $(2,3,5)$ and expressed as m $\mu$ moles bilirubin formed per $10 \mathrm{mg}$ protein in $1 \mathrm{~min}$. For computation of total organ enzyme activity, the assumption was made that all microsomal heme oxygenase activity was recovered in the $20,000 \mathrm{~g}$ supernatant fraction of the homogenate (2).

All experiments were carried out on groups of rats of similar age matched by weight. Hemoglobin was administered by a single injection into the tail vein after the animals had been lightly anesthetized with ether. The volume of fluid injected was usually about $1 \mathrm{ml}$ and never exceeded $3 \mathrm{ml}$. Control animals received an intravenous injection of isotonic saline. In most experiments, $30 \mathrm{mg}$ of hemoglobin per $100 \mathrm{~g}$ body weight was given; this dose exceeded by far the haptoglobin-binding capacity of the plasma (10), regularly led to hemoglobinuria and generally resulted in maximal stimulation of renal heme oxygenase activity. In the dose-effect studies, 5-50 $\mathrm{mg}$ of hemoglobin was injected per $100 \mathrm{~g}$ body weight.

Cyclohexamide (Sigma Chemical Co., St. Louis, Mo.), puromycin (Nutritional Biochemical Corporation, Cleveland, Ohio), or actinomycin D (Sigma Chemical Co.), were given intraperitoneally either $1 \mathrm{hr}$ before or 2 (actinomycin) or $4 \mathrm{hr}$ (cyclohexamide) after the intravenous administration of $30 \mathrm{mg}$ of hemoglobin per $100 \mathrm{~g}$ body weight; puromycin was injected hourly. Control animals received isotonic saline, given intraperitoneally at comparable times. The doses of these inhibitors used were similar to those employed in studies of $\delta$-aminolevulinic acid synthetase in rat liver (21), i.e. cyclohexamide, $1.8 \mathrm{mg}$, and actinomycin, $1.5 \mathrm{mg}$ per $\mathrm{kg}$; puromycin was given every hour in a dose of $100 \mathrm{mg}$ per $\mathrm{kg}$. To test the effectiveness of cyclohexamide in suppressing renal protein synthesis, $50 \mu \mathrm{Ci}$ of leucine- ${ }^{14} \mathrm{C}$ (New England Nuclear Corp, Boston, Mass.) was injected intravenously $1 \mathrm{hr}$ after the intraperitoneal administration of cyclohexamide given at doses that ranged from 0.3 to $2.1 \mathrm{mg}$ per $\mathrm{kg}$ body weight. $4 \mathrm{hr}$ after the isotope administration, the kidneys were removed and the ${ }^{14} \mathrm{C}$ activity in the trichloroacetic acid-precipitable fraction was determined (12). A dose of $1.8 \mathrm{mg}$ per $\mathrm{kg}$ of cyclohexamide reduced leucine $-{ }^{14} \mathrm{C}$ incorporation into soluble kidney proteins by two-thirds.

In a series of experiments, the response of the kidneys to injected native hemoglobin was compared with that of BME-treated hemoglobin; the latter is poorly filtered by the glomeruli (11) because of its tetrameric form (22). 40 rats received unlabeled hemoglobin or BME-hemoglobin intravenously at a dose of $15 \mathrm{mg}$ per $100 \mathrm{~g}$ body weight, and the hemoglobin excreted in the urine during the ensuing $4 \mathrm{hr}$ was measured. In 12 rats that had been given $30 \mathrm{mg}$ per $100 \mathrm{~g}$ body weight of hemoglobin $-{ }^{50} \mathrm{Fe}$ or $\mathrm{BME}-$ hemoglobin $-{ }^{50} \mathrm{Fe}$, plasma radioactivity was measured at 1,4 , and $8 \mathrm{hr}$ after the intravenous injection. From these values and the plasma volume estimated from the body weight (23), the total circulating radioactivity was calculated. Radioactivity excreted in the urine was compared with the excreted amount of hemoglobin, determined colorimetrically. Nine rats were depleted of their plasma haptoglobin $(10,11)$ by two preliminary intravenous injections of 10 $\mathrm{mg}$ native hemoglobin spaced $1 \mathrm{hr}$ apart. $1 \mathrm{hr}$ later, each animal received intravenously, $2 \mathrm{mg}$ of BME-treated or 2 
TABLE I

Heme Oxygenase Activity in Kidneys, Liver, and Spleen after a Single Intravenous Injection of Hemoglobin

Heme oxygenase activity

\begin{tabular}{|c|c|c|c|c|}
\hline \multirow[b]{2}{*}{ Organ } & \multicolumn{2}{|c|}{ Control } & \multicolumn{2}{|c|}{ Hemoglobin infusion } \\
\hline & $\begin{array}{c}\text { per } 10 \mathrm{mg} \\
\text { protein }\end{array}$ & $\begin{array}{l}\text { in total } \\
\text { organ }\end{array}$ & $\begin{array}{c}\text { per } 10 \mathrm{mg} \\
\text { protein }\end{array}$ & $\begin{array}{l}\text { in total } \\
\text { organ }\end{array}$ \\
\hline & \multicolumn{4}{|c|}{ mumoles bilirubin formed } \\
\hline Kidneys & $\begin{array}{c}0.03 \\
(0-0.05)\end{array}$ & $\begin{array}{c}0.22 \\
(0-0.36)\end{array}$ & $\begin{array}{c}1.08 \\
(0.86-1.19)\end{array}$ & $\begin{array}{c}8.1 \\
(7.7-9.4)\end{array}$ \\
\hline Liver & $\begin{array}{c}0.07 \\
(0.06-0.08)\end{array}$ & $\begin{array}{c}4.5 \\
(3.5-5.2)\end{array}$ & $\begin{array}{c}0.12 \\
(0.11-0.14)\end{array}$ & $\begin{array}{c}7.8 \\
(7.5-8.9)\end{array}$ \\
\hline Spleen & $\begin{array}{c}0.71 \\
(0.68-0.93)\end{array}$ & $\begin{array}{c}3.8 \\
(3.5-4.9)\end{array}$ & $\begin{array}{c}0.82 \\
(0.75-1.01)\end{array}$ & $\begin{array}{c}4.7 \\
(4.5-5.8)\end{array}$ \\
\hline
\end{tabular}

Rats were given a single intravenous injection of $30 \mathrm{mg}$ hemoglobin per $100 \mathrm{~g}$ body weight and were sacrificed $10 \mathrm{hr}$ later. Control animals received an injection of isotonic saline. Values represent mean and range of three to six individual animals in each group.

mg of native hemoglobin, labeled with ${ }^{50} \mathrm{Fe}$. The total radioactivity in the kidneys and urine was determined after $4 \mathrm{hr}$ In a similar set of experiments, 24 rats of about $250 \mathrm{~g}$ body weight were injected with $\mathrm{BME}$-treated hemoglobin${ }^{50} \mathrm{Fe}$ or with native hemoglobin $-{ }^{50} \mathrm{Fe}$ in a dose of $30 \mathrm{mg}$ per $100 \mathrm{~g}$ body weight; this larger dose was selected to permit comparison of the results with those obtained in the other experimental series. In each group, the animals were sacrificed at intervals of $\frac{1}{2}-1 \mathrm{hr}$ up to $4 \mathrm{hr}$ after receiving the isotope, and the radioactivity in both kidneys was determined. Under the assumption that most radioactivity present in the kidneys represented ${ }^{50} \mathrm{Fe}$ of hemoglobin that had been filtered and subsequently reabsorbed, it was possible to calculate the fraction of the administered hemoglobin dose that had been retained in the kidneys during each interval. In these computations, no allowance was made for radioactivity in plasma trapped within the kidneys. Heme oxygenase activity in rat kidneys was determined $6 \mathrm{hr}$ after a single intravenous injection of $\mathrm{BME}$-treated or of native hemoglobin in varying doses in order to determine the relationship between enzyme stimulation and the amount of blood pigment that was filtered and reabsorbed by the kidneys. In a group of 16 rats, heme oxygenase activity in the kidneys was compared with that in the liver $10 \mathrm{hr}$ after a single intravenous injection of $\mathrm{BME}$-treated or of native hemoglobin at a dose of $30 \mathrm{mg}$ per $100 \mathrm{~g}$ body weight.

Experiments were performed in rats and rabbits to localize the anatomical site(s) of the stimulated enzyme in the kidneys. In rats the renal cortex (light tan) was easily distinguished from the renal medulla (pink), and cortical or medullary slices could be obtained by razor blade dissection under a dissecting microscope in a cold room at $4^{\circ} \mathrm{C}$. To the extent possible, all calyceal material was removed from the medullary slices. For each enzyme assay, slices of the kidneys of seven rats were pooled; three groups of seven animals were studied. All animals were sacrificed 10 $\mathrm{hr}$ after receiving $30 \mathrm{mg}$ of hemoglobin per $100 \mathrm{~g}$ body weight.

Four rats were injected intravenously either with $30 \mathrm{mg}$ hemoglobin per $100 \mathrm{~g}$ body weight or with an equivalent volume of isotonic saline. The animals were sacrificed 10 hr later, and the kidneys were removed and placed in $10 \%$ formaldehyde in isotonic saline. Thin sections of the kidneys were stained with hematoxylin and eosin for histological examination.

Three female New Zealand white rabbits of $3-3.5 \mathrm{~kg}$ body weight were injected in a marginal ear vein with rabbit hemoglobin (60 $\mathrm{mg}$ per $\mathrm{ml}$ saline) in a dose of $30-35$ mg per $100 \mathrm{~g}$ body weight. The rabbits were sacrificed 10 $\mathrm{hr}$ later by intravenous injection of air, and the kidneys were removed immediately and placed in ice-cold Hank's solution. Slices of $1.5-2 \mathrm{~mm}$ thickness were cut through the center of the decapsulated kidneys with a razor blade. The slices were put in a Petri dish containing ice-cold Hank's solution and were oxygenated by a bubbling gas mixture of $95 \%$ oxygen and $5 \%$ carbon dioxide. Clean proximal renal tubules were dissected from the cortex inward, using fine forceps and a stereoscopic microscope with 20 to 40 times magnification at room temperature. The

BILIRUBIN FORMED

$\mathrm{m \mu}$ moles/10 mg protein/min

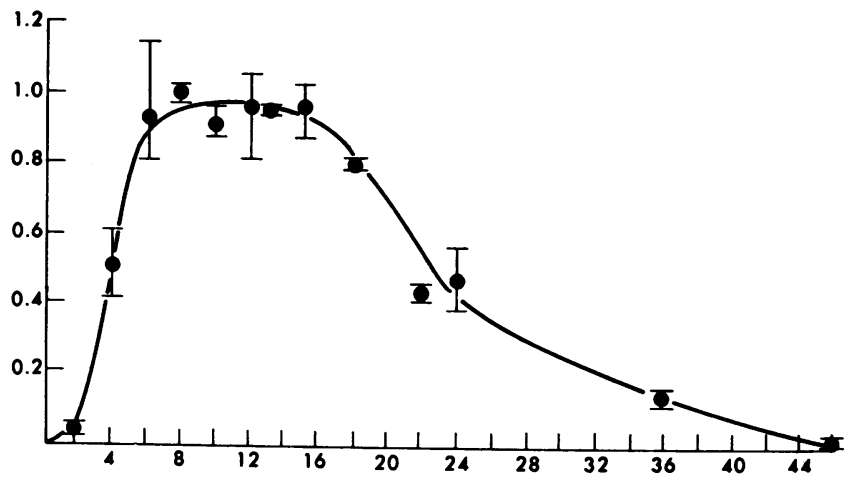

HOURS AFTER HEMOGIOBIN ADMINISTRATION

FIGURE 1 Heme oxygenase activity in rat kidneys after a single intravenous injection of $30 \mathrm{mg}$ hemoglobin per $100 \mathrm{~g}$. Each point represents the mean value of two to five individual animals, the vertical bars representing the range of values. 


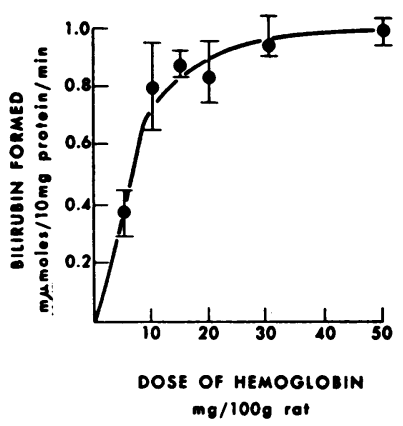

FIgURE 2 Heme oxygenase activity in rat kidneys $6 \mathrm{hr}$ after a single intravenous injection of hemoglobin in varying doses. Each point represents the mean value of three to five individual animals, the vertical bars representing the range of values.

tubules were homogenized and microsomal heme oxygenase was assayed in a $20,000 \mathrm{~g}$ supernatant fraction, using a microassay method based on isotope dilution (24).

\section{RESULTS}

Response of renal heme oxygenase to a single intravenous injection of hemoglobin. In confirmation of our previous report (5), renal heme oxygenase activity in untreated or saline-injected rats was found to be very low (Table I). Following a single intravenous injection of hemoglobin, enzyme activity in the kidneys remained low for an initial $2 \mathrm{hr}$, but then rose steeply to reach peak values between 6 and $16 \mathrm{hr}$ (Fig. 1). During the subsequent $30 \mathrm{hr}$, heme oxygenase activity gradually returned to preinjection levels (Fig. 1). At maximal stimulation, the total enzyme activity in the kidneys of hemoglobin-treated animals equaled or exceeded that in the spleen or the liver (Table I).

The response of renal heme oxygenase activity $6 \mathrm{hr}$ after a single intravenous injection of hemoglobin at different dose levels (Fig. 2) was characteristic of most dose-response curves and was linear to about $10 \mathrm{mg}$ hemoglobin per $100 \mathrm{~g}$ body weight.

Since these time and dose-response curves were consistent with substrate-mediated enzyme induction, experiments were carried out with inhibitors of protein or ribonucleic acid (RNA) synthesis. Cyclohexamide, puromycin, or actinomycin $\mathrm{D}$, given $1 \mathrm{hr}$ before the injection of hemoglobin, greatly reduced or abolished the stimulatory effect of hemoglobin on renal heme oxygenase activity (Fig. 3). Moreover, when cyclohexamide was given $4 \mathrm{hr}$ after the hemoglobin injection, i.e. at a time when renal uptake of hemoglobin was virtually completed, the further stimulation of the enzyme was severely blunted (Fig. 4). Similarly, actinomycin D given $2 \mathrm{hr}$ following the hemoglobin administration, abolished after a short lag period, the stimulation of heme oxygenase activity in the kidneys (Fig. 5). The findings

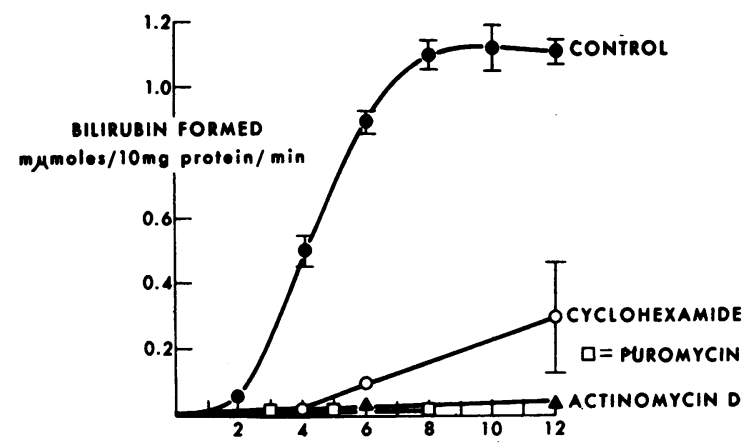

HOURS AFTER HEMOGLOBIN ADMINISTRATION

Figure 3 Heme oxygenase activity in rat kidneys after a single intravenous injection of $30 \mathrm{mg}$ hemoglobin per $100 \mathrm{~g}$. Cyclohexamide, puromycin, or actinomycin D was given intraperitoneally $1 \mathrm{hr}$ before the hemoglobin injection; puromycin was given hourly thereafter. Control animals received injections of isotonic saline instead of the metabolic inhibitors. Each point represents the average value of two individual animals, the vertical bars representing the range of values.

with these metabolic inhibitors suggest that the hemoglobin-mediated stimulation of enzyme activity is dependent on the continued synthesis of renal RNA and protein. The slope of the declining enzyme activity after cyclohexamide (Fig. 4) approximates first order kinetics and suggests an apparent half-life for the renal enzyme of about $6 \mathrm{hr}$.

Relationship of renal heme oxygenase activity to glomerular filtration of hemoglobin. In order to further characterize the relationship between renal heme oxygenase activity and hemoglobin in the kidney, a series of experiments were carried out with BME-treated hemoglobin which is poorly filtered by the glomeruli (11). The following findings were obtained: $(a)$ in 40 rats

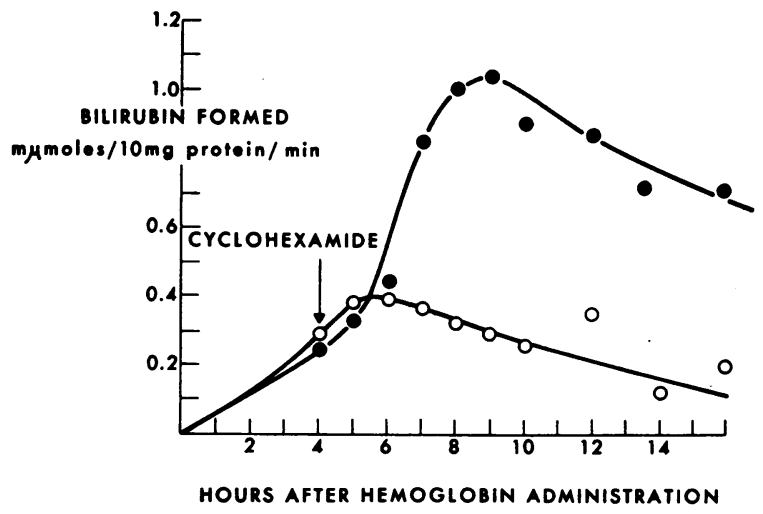

FIGURE 4 Heme oxygenase activity in rat kidneys after a single intravenous injection of $30 \mathrm{mg}$ hemoglobin per $100 \mathrm{~g}$. Cyclohexamide (open circles) was given intraperitoneally $4 \mathrm{hr}$ after the injection of hemoglobin. Control animals (closed circles) received an injection of isotonic saline. 


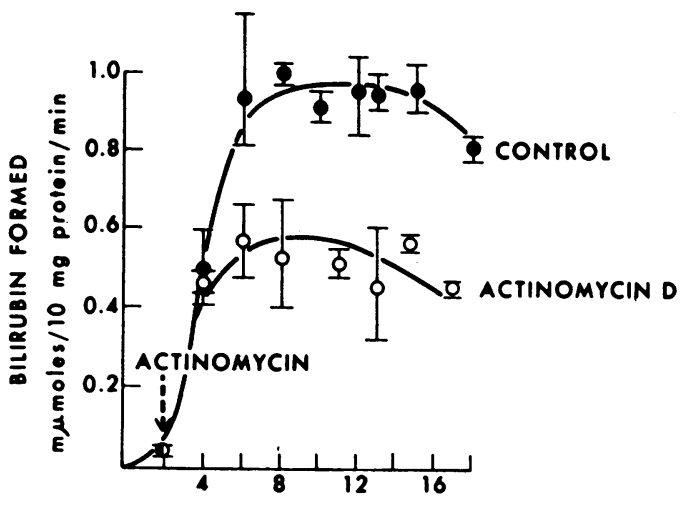

HOURS AFTER HEMOGLOBIN ADMINISTRATION

FIgURe 5 Heme oxygenase activity in rat kidneys after a single intravenous injection of $30 \mathrm{mg}$ hemoglobin per $100 \mathrm{~g}$. Actinomycin D (open circles) was given intraperitoneally $2 \mathrm{hr}$ after the injection of hemoglobin; control animals (closed circles) received an injection of isotonic saline. One group of animals was sacrificed approximately $5 \mathrm{~min}$ after the administration of the actinomycin or saline. Each point represents the mean of two to five individual animals, the vertical bars representing the range of values.

that were injected with native or BME-treated hemoglobin in doses of $15 \mathrm{mg}$ per $100 \mathrm{~g}$ rat, hemoglobinuria was significantly less with the BME-hemoglobin (0.5 $\mathrm{mg}$, sD 0.05 , in $4 \mathrm{hr}$ ) than with the native unreacted hemoglobin (4.4 $\mathrm{mg}$, sD 1.95 , in $4 \mathrm{hr}$ ) (25). (b) The rate of disappearance of BME-treated hemoglobin from the circulation was much slower than that of native hemoglobin (Table II). (c) In five haptoglobin-depleted rats, $49 \%$ (range $48-52 \%$ ) of a small dose $(2 \mathrm{mg}$ ) of hemoglobin- ${ }^{50} \mathrm{Fe}$ was taken up by the kidneys in $4 \mathrm{hr}$. Comparable values with four rats given BME-treated hemoglobin were less than $5 \%$ (range 1.6-4.5\%). Almost no radioactivity was detectable in the urine of these rats during the $4 \mathrm{hr}$ of the study. (d) When native

TABLE II

Hemoglobin- ${ }^{59} \mathrm{Fe}$ Retained in Circulating Plasma after a Single Intravenous Injection of Radioactive Hemoglobin in Rats

\begin{tabular}{lccc}
\hline \multirow{2}{*}{ Hemoglobin injected } & \multicolumn{3}{c}{ Dose retained in circulation } \\
\cline { 2 - 4 } & $1 \mathrm{hr}$ & $4 \mathrm{hr}$ & $8 \mathrm{hr}$ \\
\hline \multirow{2}{*}{ Hemoglobin- ${ }^{59} \mathrm{Fe}$} & 18 & $\%$ & \\
& $(14-22)$ & $(3-5)$ & $(0-2)$ \\
BME-treated hemoglobin- ${ }^{59} \mathrm{Fe}$ & 50 & 30 & 14 \\
& $(42-58)$ & $(28-32)$ & $(12-16)$
\end{tabular}

Each value represents the average of two individual experiments. The range of values in each group is given in brackets. hemoglobin ${ }^{50} \mathrm{Fe}$ or $\mathrm{BME}$-treated hemoglobin ${ }^{50} \mathrm{Fe}$ was injected in a dose of $30 \mathrm{mg}$ per $100 \mathrm{~g}$ body weight, the radioactivity after $4 \mathrm{hr}$ in the kidneys of the rats given BME-hemoglobin was about one-third less than in animals that had received native hemoglobin (Fig. 6). In all instances, the rate of renal isotope uptake was rapid, and was nearly completed in $4 \mathrm{hr}$.

These observations confirm the report by Bunn et al. (11) that complexing of hemoglobin with the sulfhydryl reagent $\mathrm{BME}$ greatly reduces its glomerular filtration, minimizes hemoglobinuria, and prolongs the hemoglobinemia.

When rats were injected with varying doses of BMEtreated hemoglobin, the stimulatory effect on renal heme oxygenase activity was significantly less at all dose levels than with native hemoglobin (Fig. 7). By contrast, the pattern of enzyme stimulation in the liver was reversed, in that hepatic heme oxygenase activity was higher after injection of BME-treated hemoglobin than after native hemoglobin. Thus, in eight rats given $30 \mathrm{mg}$ per $100 \mathrm{~g}$ body weight of BME-hemoglobin, enzyme activity ( $\mathrm{m} \mu$ moles bilirubin/10 $\mathrm{mg}$ protein per $\mathrm{min}$ ) after $10 \mathrm{hr}$ in the liver was $0.44(0.04 \mathrm{SE})$ and in the kidney $0.68(0.11 \mathrm{SE})$. The respective values after administration of a comparable amount of native hemoglobin to eight rats were: liver $0.13(0.007 \mathrm{SE})$, and kidneys $1.07(0.06 \mathrm{SE})$. These results are significantly different at the $P<0.005$ level (25).

Anatomical localization of stimulated renal heme oxygenase activity. When renal cortex and medulla of hemoglobin-injected rats were assayed separately for heme oxygenase activity, most of the enzyme activity was found in the cortical tissue, with only traces present in the medulla (Fig. 8). On histological examina-

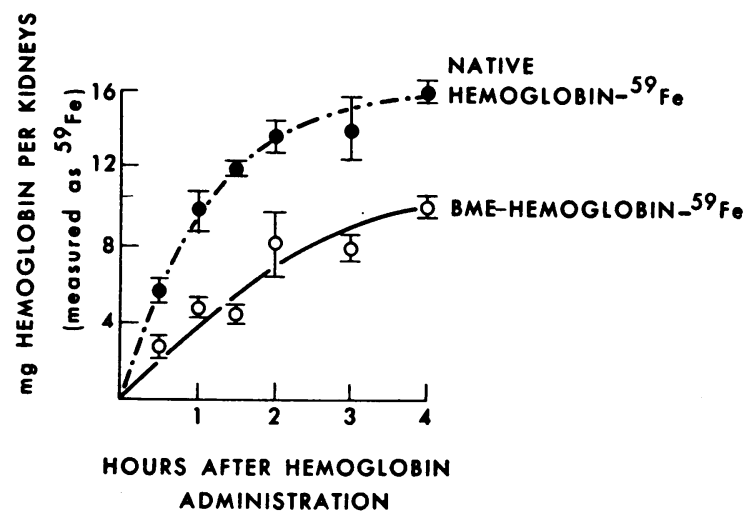

Figure 6 Hemoglobin- ${ }^{50} \mathrm{Fe}$ in rat kidneys after intravenous injection of native hemoglobin- ${ }^{50} \mathrm{Fe}$ (closed circles) or BME-treated hemoglobin ${ }^{50} \mathrm{Fe}$ (open circles) at a dose of $30 \mathrm{mg}$ per $100 \mathrm{~g}$. The results, measured as ${ }^{80} \mathrm{Fe}$ in the two kidneys, are expressed as milligrams hemoglobin. Each point represents the average of two individual experiments, the vertical bars representing the range of values. 


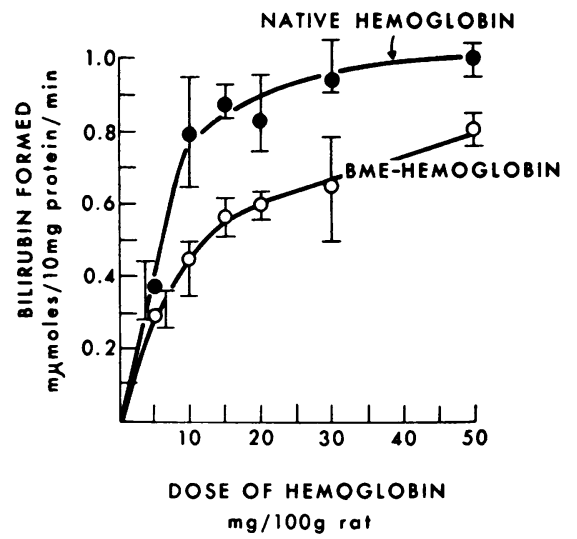

Figure 7 Heme oxygenase activity in rat kidneys $6 \mathrm{hr}$ after a single intravenous injection of native hemoglobin (closed circles) or BME-treated hemoglobin (open circles) in varying doses. Each point represents the mean value of three to five individual animals, the vertical bars representing the range of values.

tion of hematoxylin and eosin-stained sections of kidneys obtained $10 \mathrm{hr}$ after hemoglobin injection, the morphology of the nephron and the surrounding vessels appeared normal and there was no evidence of mononuclear cell infiltration.

The kidneys of the three rabbits injected with hemoglobin exhibited heme oxygenase activity (Table III) comparable with that of stimulated rat kidney (Table I). In the proximal tubules dissected from these kidneys (equivalent to $0.04-0.07 \mathrm{mg}$ of protein), heme oxygenase activity of the microsomal fraction was slightly higher than in the comparable fraction obtained from the whole kidneys (Table III). In tubular preparations obtained from control rabbits, no heme oxygenase activity was detectable.

\section{DISCUSSION}

The present results establish that the kidneys of rats and rabbits possess an enzymatic mechanism for the conversion of heme to bilirubin. This finding might have been anticipated, as Ostrow, Jandl, and Schmid (26) had shown that after infusion of ${ }^{50} \mathrm{Fe}-,{ }^{14} \mathrm{C}$-labeled hemoglobin in rats, even when nearly half of the isotopic iron was retained in the kidneys, the heme- ${ }^{14} \mathrm{C}$ activity administered was almost quantitatively converted to bilirubin ${ }^{14} \mathrm{C}$ excreted in the bile. Furthermore, the observations of Keene and Jandl (17) indicated that when plasma hemoglobin levels exceed the haptoglobin-binding capacity, the kidneys become a major site of hemoglobin uptake in the rat. More recently, Bunn and Jandl (12) demonstrataed by means of serial extractions, that hemoglobin, absorbed by the renal parenchyma, rapidly disappears from the kidneys leaving behind the iron moiety, which is mobilized more slowly. Finally, in chronic

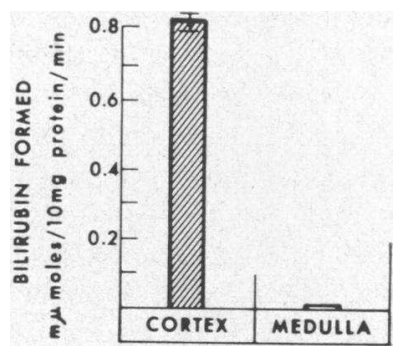

FIGURE 8 Heme oxygenase activity in renal cortex and medulla of rats injected $10 \mathrm{hr}$ earlier with $30 \mathrm{mg}$ hemoglobin per $100 \mathrm{~g}$. Bracket represents range of values in three groups of seven animals each.

intravascular hemolysis, such as paroxysmal nocturnal hemoglobinuria, hemosiderin, presumably derived from iron-laden tubular cells (27), frequently appears in the urine (28). These observations suggested that in hemoglobinemia resulting in hemoglobinuria, the kidneys may play a major role in the catabolism of hemoglobin.

In tissues ordinarily concerned with the removal and degradation of senescent red cells, the heme of hemoglobin is converted to bile pigment by a microsomal heme oxygenase system (2-4). In vitro studies indicate that this enzyme can utilize as substrates only heme or easily dissociable heme-protein complexes (3). Thus, the enzymatic degradation of hemoglobin or of intracellular hemoproteins is probably governed first by factors that modify the hemoprotein to increase its dissociation constant. Heme oxygenase activity must then be coordinated with this process. An enzymatic apparatus exhibiting very similar properties and subcellular localization has now been demonstrated in the kidneys. However, under physiological conditions, renal heme oxygenase activity is very low but is increased manyfold following the filtration of plasma hemoglobin into the urine. This is reminiscent of the elevated heme oxygenase activity in the liver after splenectomy or experimental hemolysis $(4,5)$ and of the stimulation of the enzyme in macrophages that have ingested heme or he-

TABLE III

Heme Oxygenase Activity in Whole Kidneys and in Isolated Renal Tubules of Rabbits Injected Intravenously with Hemoglobin

\begin{tabular}{ccc}
\hline & \multicolumn{2}{c}{ Heme oxygenase activity } \\
\cline { 2 - 3 } Rabbit & Whole kidney & Renal tubules \\
\hline & mumoles bilirubin formed \\
1 & 10 mg protein per min \\
2 & 1.2 & $1.5^{*}$ \\
3 & 0.9 & 1.2 \\
& 0.8 & 1.0 \\
\hline
\end{tabular}

* Average of duplicate determinations.

Heme Oxygenase in the Kidney 
moglobin in vivo before being harvested (9). In the present study, the characteristics of the time and doseresponse curves of renal heme oxygenase after a single intravenous injection of hemoglobin, and the inhibitory effects of cyclohexamide, puromycin, and actinomycin D strongly suggest that this functional adaptation of the enzyme reflects induction of heme oxygenase by its substrate, hemoglobin. The effect of these metabolic inhibitors cannot be ascribed solely to impaired glomerular filtration or tubular reabsorption of hemoglobin as the inhibitors effectively thwarted further stimulation of enzyme activity when they were given after the hemoglobin had been taken up by the kidneys.

The apparent half-life of microsomal heme oxygenase in the kidney, as calculated from these curves, is about $6 \mathrm{hr}$. This is significantly less than that reported for other microsomal enzymes involved in mixed function oxidations, such as NADPH-dependent cytochrome $c$ reductase (29) for which a half-life of as low as $30 \mathrm{hr}$ has been reported (30). The short biological halflife of microsomal heme oxygenase is surprising, but may serve to underscore the previously reported differences $(3,5)$ between the microsomal enzyme systems that catalyze the oxidation of drugs and of heme.

In the previous studies of the enzymatic conversion of heme to bilirubin (2-5), heme oxygenase activity was identified in tissues that were known to contain mesenchymal cells with phagocytic properties such as the spleen $(2-5)$ or liver $(4,5)$ or in isolated macrophages harvested from the peritoneal cavity or the lungs of rodents (9). These findings were consistent with the postulate that hemoglobin catabolism is primarily a function of the reticuloendothelial system $(31,32)$. It might have been expected, therefore, that heme oxygenase activity in the kidney also would be localized in phagocytic cells of mesenchymal origin located perhaps in the glomerular capillary loop or in the interstitial tissue of the renal medulla. However, the following findings point to the renal tubules as a major site of enzyme localization. In hemoglobinuric rats, heme oxygenase activity in the kidneys is confined almost entirely to the renal cortex (Fig. 8) which on histological examination showed no mononuclear cell infiltration. Functional studies with BME-treated hemoglobin also were in line with the concept that the enzyme activity is in the tubules rather than in the glomeruli. When hemoglobin was stabilized in its tetrameric form with $\mathrm{BME}$, its glomerular filtration was minimized, less was taken up by the kidneys (Fig. 6) or lost in the urine, and consequently, the plasma level remained elevated for a longer time (Table II). While administration of both BME-treated hemoglobin and native hemoglobin resulted in increased renal heme oxygenase activity (Fig. 7), the stimulation in rats receiving the BME-treated hemoglobin was significantly less than in animals given the native hemoglobin. This is consistent with the postulate that heme oxygenase activity in the kidney is regulated by filtered hemoglobin that has been reabsorbed by the renal tubules, rather than by the plasma hemoglobin level. That BME-treated hemoglobin is a potent stimulator of heme oxygenase was demonstrated in the liver, where enzyme activity was considerably higher after the infusion of BMEtreated hemoglobin than after equivalent amounts of native hemoglobin, reflecting the delayed plasma clearance of the former.

Direct confirmation that heme oxygenase activity can be stimulated in proximal tubular cells was obtained by enzyme assay of tubular preparations isolated from the renal cortex of rabbits that had been given intravenous injections of hemoglobin. The measurement of heme oxygenase activity in the small amount of protein available with these preparations required the use of a newly developed microassay for the enzyme which is described by one of us (R. T.) in detail elsewhere. It was noted that the specific activity of heme oxygenase in isolated renal-tubular preparations was only slightly higher than that in the whole organ. This may not be surprising in view of the fact that clean dissection of renal tubules in amounts sufficient for enzyme assay required approximately $2 \mathrm{hr}$, during which time considerable enzyme activity may have been lost. This probably should be taken into account in comparing heme oxygenase activity in whole kidneys with that in isolated tubular preparations. Moreover, the possible lability of the enzyme system makes it difficult to exclude the presence of some degree of heme oxygenase activity in any tissue structure whose isolation requires prolonged exposure to room temperature. Since hemoproteins are ubiquitous and turn over continuously, the existence of enzymatic mechanisms capable of degrading heme may indeed by postulated for all cell types.

The demonstration of heme oxygenase activity in the proximal tubules of the kidney extends previous morphologic $(12,13)$ and functional $(14,15)$ observations which indicated that filtered hemoglobin in part may be reabsorbed and catabolized in the renal tubular apparatus. Although in hemoglobinuria this catabolic mechanism may be adaptively increased, the functional significance of this adaptive response for the preservation of the body's iron stores appears to be limited. In chronic mild hemoglobinemia, when the plasma haptoglobinbinding capacity is low or exhausted, the inducible heme oxygenase system in the renal tubules may serve to reduce hemoglobinuria thereby minimizing renal iron loss. It is apparent, however, that when the filtered load of hemoglobin is increased, this homeostatic mechanism is easily overwhelmed and thus rendered relatively ineffective. The role of the adaptive heme oxygenase system 
of the kidney in the multifactorial pathogenesis of hemoglobinuric nephropathy (33-35) is unclear.

The presence of heme oxygenase activity in the tubular cells of the kidney, which are of epithelial origin, indicates that the enzymatic capacity to convert heme to bilirubin is not limited to phagocytic cells of mesenchymal origin. This is consistent with the previously presented inferential evidence that bilirubin may be formed in the hepatic parenchymal cells (5). Thus, "early-labeled" bilirubin excreted in the bile (36), appears to reflect largely, turnover of heme and hemoproteins that are formed and broken down in the hepatocytes $(37,38)$; this turnover and consequently, the rate of bilirubin formation may be enhanced significantly by treatment with drugs such as phenobarbital (39). It also is attractive to speculate that heme oxygenase may be present in the epithelial cells of the gut mucosa. In the intestines of blood sucking arthropods, the cells lining the mucosal surface have been observed to contain biliverdin (40). In carnivorous and omnivorous mammals, hemoglobiniron that has reached the intestine may in part be absorbed and reutilized (41-45); the ferroprotoporphyrin appears to be cleaved after it has been absorbed by the intestinal mucosa but before the iron is released into the plasma (42-45). Although various mechanisms have been proposed to explain this phenomenon (43-45), heme oxygenase in the epithelial cells of the intestinal mucosa would appear to be a likely possibility.

\section{ACKNOWLEDGMENTS}

This study was supported in part by U. S. Public Health Service Research Grant AM-11275, U. S. Public Health Service Training Grant AM-05598, and the Walter C. Pew Fund for Gastrointestinal Research.

\section{REFERENCES}

1. Pimstone, N. R., P. Engel, P. T. Seitz, H. S. Marver, and R. Schmid. 1970. Inducible heme oxygenase in the kidney: a model for the homeostatic control of hemoglobin catabolism. J. Clin. Invest. 49: 74a. (Abstr.)

2. Tenhunen, R., H. S. Marver, and R. Schmid. 1968. The enzymatic conversion of heme to bilirubin by microsomal heme oxygenase. Proc. Nat. Acad. Sci. U. S. A. 61: 748.

3. Tenhunen, R., H. S. Marver, and R. Schmid. 1969. Microsomal heme oxygenase. Characterization of the enzyme. J. Biol. Chem. 244: 6388.

4. Tenhunen, R., H. S. Marver, and R. Schmid. 1969. The enzymatic conversion of hemoglobin to bilirubin. Trans. Ass. Amer. Physicians Philadelphia. 82: 363.

5. Tenhunen, R., H. S. Marver, and R. Schmid. 1970. The enzymatic catabolism of hemoglobin: stimulation of microsomal heme oxygenase by hemin. J. Lab. Clin. Med. $75: 410$.

6. Tenhunen, R., M. E. Ross, H. S. Marver, and R. Schmid. 1970. Reduced nicotinamide-adenine dinucleotide phosphate-dependent biliverdin reductase. Partial purification and characterization. Biochemistry. 9: 298.

7. Colleran, E., and P. OCarra. 1970. Specificity of biliverdin reductase. Biochem. J. 119: 16p. (Abstr.)
8. Jandl, J. H., A. R. Jones, and W. B. Castle. 1957. Destruction of red cells by antibodies in man. I. Observations on the sequestration and lysis of red cells altered by immune mechanisms. J. Clin. Invest. 36: 1428.

9. Pimstone, N. R., R. Tenhunen, P. T. Seitz, R. Schmid, and H. S. Marver. 1971. The enzymatic degradation of hemoglobin to bile pigment by macrophages. J. Exp. Med. 133: 1264

10. Gabrieli, E. R., P. Heckert, and A. Elliott. 1962. Kinetics of plasma hemoglobin catabolism in the rat. I. Blood clearance of $\mathrm{I}^{181}$-tagged hemoglobin. Proc. Soc. Exp. Biol. Med. 109: 787.

11. Bunn, H. F., W. T. Esham, and R. W. Bull. 1969. The renal handling of hemoglobin. I. Glomerular filtration. J. Exp. Med. 129: 909.

12. Bunn, H. F., and J. H. Jandl. 1969. The renal handling of hemoglobin. II. Catabolism. J. Exp. Med. 129: 925.

13. Ericsson, J. L. E. 1964. Absorption and decomposition of homologous hemoglobin in renal proximal tubular cells. Acta Pathol. Microbiol. Scand. Suppl. 68: 1.

14. Miller, F. 1960. Hemoglobin absorption by the cells of the proximal convoluted tubule in mouse kidney. $J$. Biophys. Biochem. Cytol. 8: 689.

15. Lathem, W., B. B. Davis, P. H. Zweig, and R. Dew. 1960. The demonstration and localization of renal tubular reabsorption of hemoglobin by stop flow analysis. $J$. Clin. Invest. 39: 840.

16. Malmendier, C. L., J. P. DeKoster, F. Vander Veiken, H. Brauman, M. D. Mayttenaere, and P. Lambert. 1960. Stop-flow analysis applied to the excretion of hemoglobin. Amer. J. Physiol. 199: 292.

17. Keene, W. R., and J. H. Jandl. 1965. The sites of hemoglobin catabolism. Blood. 26: 705.

18. Boyer, P. D. 1954. Spectrophotometric study of the reaction of protein sulfhydryl groups with organic mercurials. J. Amer. Chem. Soc. 76: 4331.

19. Crosby, W. H., and D. N. Houchin. 1957. Preparing standard solutions of cyanmethemoglobin. Blood. 12: 1132.

20. Crosby, W. H., and F. W. Furth. 1956. A modification of the benzidine method for measurement of hemoglobin in plasma and urine. Blood. 11: 380.

21. Marver, H. S., A. Collins, D. P. Tschudy, and $M$. Rechcig1, Jr. 1966. $\delta$-Aminolevulinic acid synthetase. II. Induction in rat liver. J. Biol. Chem. 241: 4323.

22. Simon, S. R., and W. H. Konigsberg. 1966. Chemical modification of hemoglobins: a study of conformation restraint by internal bridging. Proc. Nat. Acad. Sci. U.S. A. 56: 749.

23. Keene, W. R., and J. H. Jandl. 1965. Studies of the reticuloendothelial mass and sequestering function of rat bone marrow. Blood. 26: 157.

24 Tenhunen, R. 1971. Method for microassay of microsomal heme oxygenase activity. Anal. Biochem. In press.

25. Snedecor, G. W., and W. G. Cochran. 1967. In Statistical Methods. Iowa State University Press, Ames, Iowa. 6th edition.

26. Ostrow, J. D., J. H. Jandl, and R. Schmid. 1962. The formation of bilirubin from hemoglobin in vitro. $J$. Clin. Invest. 41: 1628.

27. Crosby, W. H. 1953. Paroxysmal nocturnal hemoglobinuria. Relation of the clinical manifestations to underlying pathogenic mechanisms. Blood. 8: 769.

28. Crosby, W. H., and W. Dameshek. 1951. The significance of hemoglobinemia and associated hemosiderinuria 
with particular reference to various types of hemolytic anemia. J. Lab. Clin. Med. 38: 829.

29. Gillette, J. R., and T. E. Gram. 1969. Cytochrome P-450 reduction in liver microsomes and its relationship to drug metabolism. In Microsomes and Drug Oxidation. J. R. Gillette et al., editors. Academic Press Inc., New York. 133.

30. Kuriyama, Y., T. Omura, P. Siekevitz, and G. E. Palade. 1969. Effects of phenobarbital on the synthesis and degradation of the protein components of rat liver microsomal membranes. J. Biol. Chem. 244: 2017.

31. Rich, A. R. 1925. The formation of bile pigment. Physiol. Rev. 5: 182.

32. Miescher, P. 1957. The role of the reticulo-endothelial system in haematoclasia. In Physiopathology of the Reticulo-endothelial System; a Symposium. B. N. Halpern, editor. Blackwell Scientific Publications Ltd., Oxford, England. 147.

33. Braun, S. R., F. R. Weiss, A. I. Keller, J. R. Ciccone, and H. G. Preuss. 1970. Evaluation of the renal toxocity of heme proteins and their derivatives: a role in the genesis of acute tubule necrosis. J. Exp. Med. 131: 443.

34. Jaenike, J. R., and E. E. Schneeberger. 1966. The renal lesion associated with hemoglobinemia. II. Its structural characteristics in the rat. J. Exp. Med. 123: 537.

35. Jaenike, J. R. 1967. The renal lesion associated with hemoglobinemia: a study of the pathogenesis of the excretory defect in the rat. J. Clin. Invest. 46: 378 .

36. Robinson, S. H. 1968. The origins of bilirubin. N. Engl. J. Med. 279: 143.
37. Landaw, S. A., and H. S. Winchell. 1970. Endogenous production of ${ }^{14} \mathrm{CO}$ : a method for calculation of $\mathrm{RBC}$ life-span in vivo. Blood. 36: 642.

38. Robinson, S. H., C. A. Owen, Jr., E. V. Flock, and R. Schmid. 1965. Bilirubin formation in the liver from nonhemoglobin sources. Experiments with isolated, perfused rat liver. Blood. 26: 823 .

39. Schmid, R., H. S. Marver, and L. Hammaker. 1966. Enhanced formation of rapidly labeled bilirubin by phenobarbital: hepatic microsomal cytochromes as a possible source. Biochem. Biophys. Res. Commun. 24: 319.

40. Wigglesworth, V. A. 1943. The fate of haemoglobin in Rhodnius prolixus (Hemiptera) and other blood sucking arthropods. Proc. Roy Soc. Ser. B. 131: 313.

41. Conrad, M. E., B. I. Benjamin, H. L. Williams, and A. L. Foy. 1967. Human absorption of hemoglobin-iron. Gastroenterology. 53: 5 .

42. Brown, E. B., Y.-F. Hwang, S. Nicol, and J. Ternberg. 1968. Absorption of radioiron-labeled hemoglobin by dogs. J. Lab. Clin. Med. 72: 58.

43. Awai, M., and E. B. Brown. 1969. Examination of the role of xanthine oxidase in iron absorption by the rat. J. Lab. Clin. Med. 73: 366

44. Wheby, M. S., G. E. Sutt!e, and K. T. Ford III. 1970. Intestinal absorption of hemoglobin iron. Gastroenterology. 58: 647 .

45. Dawson, R. B., S. Rafal, and L. R. Weintraub. 1970. Absorption of hemoglobin iron. The role of xanthine oxidase in the intestinal heme-splitting reaction. Blood. 35: 94 . 